\title{
Some morphological features related to mandibular third molar impaction
}

\author{
Göksel Şimşek Kaya' ${ }^{1}$, Muzaffer Aslan ${ }^{1}$, Mehmet Melih Ömezli², Ertunç Dayı ${ }^{3}$
}

\footnotetext{
${ }^{1}$ Assistant Professor, Department of Oral and Maxillofacial Surgery, Faculty of Dentistry, Atatürk University.

${ }^{2}$ Research Assistant, Department of Oral and Maxillofacial Surgery, Faculty of Dentistry, Atatürk University.

${ }^{3}$ Professor, Department of Oral and Maxillofacial Surgery, Faculty of Dentistry, Atatürk University.
}

Correspondence:

Dr. Göksel Simşek Kaya

Atatürk University,

25240 Erzurum (Turkey)

E-mail address: gokselsimsek@yahoo.com

Received: $18 / 01 / 2010$

Accepted: 26/02/2010
Kaya GS, Aslan M, Ömezli MM, Dayı E. Some morphological features related to mandibular third molar impaction. J Clin Exp Dent. 2010;2(1):e12-7.

http://www.medicinaoral.com/odo/volumenes/v2i1/jcedv2ilp12.pdf

Article Number: $678939 \quad$ http://www.medicinaoral.com/odo/indice.htm (C) Medicina Oral S. L. C.I.F. B 96689336 - eISSN: 1989-5488

eMail: jced@jced.es

\begin{abstract}
Objective: The aim of this study was to evaluate the effect of some morphological features of the mandible and mandibular permanent molars on impaction of mandibular third molars with panoramic measurements in a Turkish patient group.

Study design: Standardized panoramic radiography variables compiled from 140 patients retrospectively were evaluated. Predictive variables included mesio-distal crown width and inclination of the mandibular molars, vertical and horizontal surface dimension between distal surface of the lower second molar tooth and anterior surface of its ramus, length and width of the mandible ramus and corpus, angle of the mandible gonion, the number of the lower third molar roots, and angulations of roots of the lower third molars.

Results and Conclusions: According to the data obtained in this study, the vertical height of the anterior border of the ramus, length of the posterior basal corpus, mesio-distal diameters of the first, second and the third molars, $1 / 3$ root angle of the third molar, number of third molar roots, inclination of the first molar to increase, vertical height of the posterior border of the ramus, vertical height of alveolar crest, and height and the width of the retro-molar space to decrease are all in direct proportion to the possibility of impaction of the third molar.
\end{abstract}

Key words: Impaction, mandibular third molar, morphological feature.

*This study was presented at the 2nd. International Oral and Maxillofacial Surgery Society Congress, Antalya, 2008. 


\section{Introduction}

Mandibular third molars (MTMs), or wisdom teeth, are the most frequently congenitally impacted teeth $(1,2)$. Although MTM, normally erupt at ages ranging from 16 to 24 (mean: 20) when they are in appropriate occlusion, about $40 \%$ of cases are partially or completely impacted (1-4).

Retention of the MTM is important for its role in orthodontic anchorage, prosthetic abutment and transplantation (2). The reported percentage of pathological changes such as infection, pain, caries, root resorption, cysts and benign or malign tumors $(5,6)$ is not high, but eruption failure usually causes irreversible damage even after mandibular third molars have been removed (7). On account of this dilemma, the indications for asymptomatic MTMs, extraction is a controversial topic among clinicians (8). While deciding upon the necessi- ty for extraction, in addition to the potential complications, it is important that morphological factors are taken into account. Since first proposed in 1936 by Henry and Morant, the prediction models have been improved (9). The objective of this study was to evaluate the effects of some morphological features of the mandible and mandibular permanent molars on impaction of MTMs with panoramic measurements in a Turkish patient group.

\section{Material and Methods}

Subjects

This retrospective study was carried out by evaluation of panoramic radiographs from 140 patients (64 male, 76 female) who presented at our oral and maxillofacial surgery services from 1998 to 2007. The patient selection criteria for panoramic radiography were intact dental arches, radiologically confirmed MTMs besides having

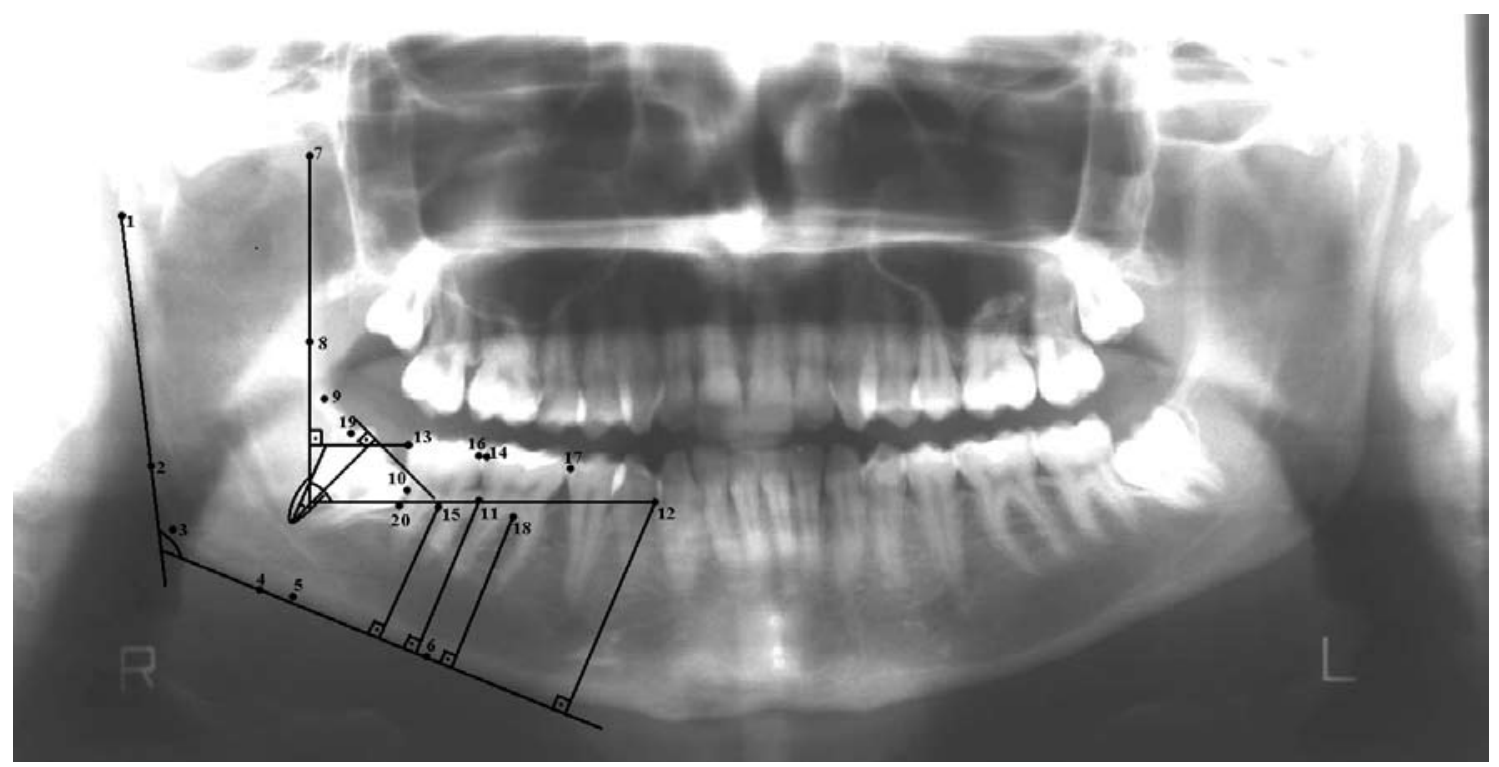

Fig. 1. Panoramic view of impacted mandibular third molar.

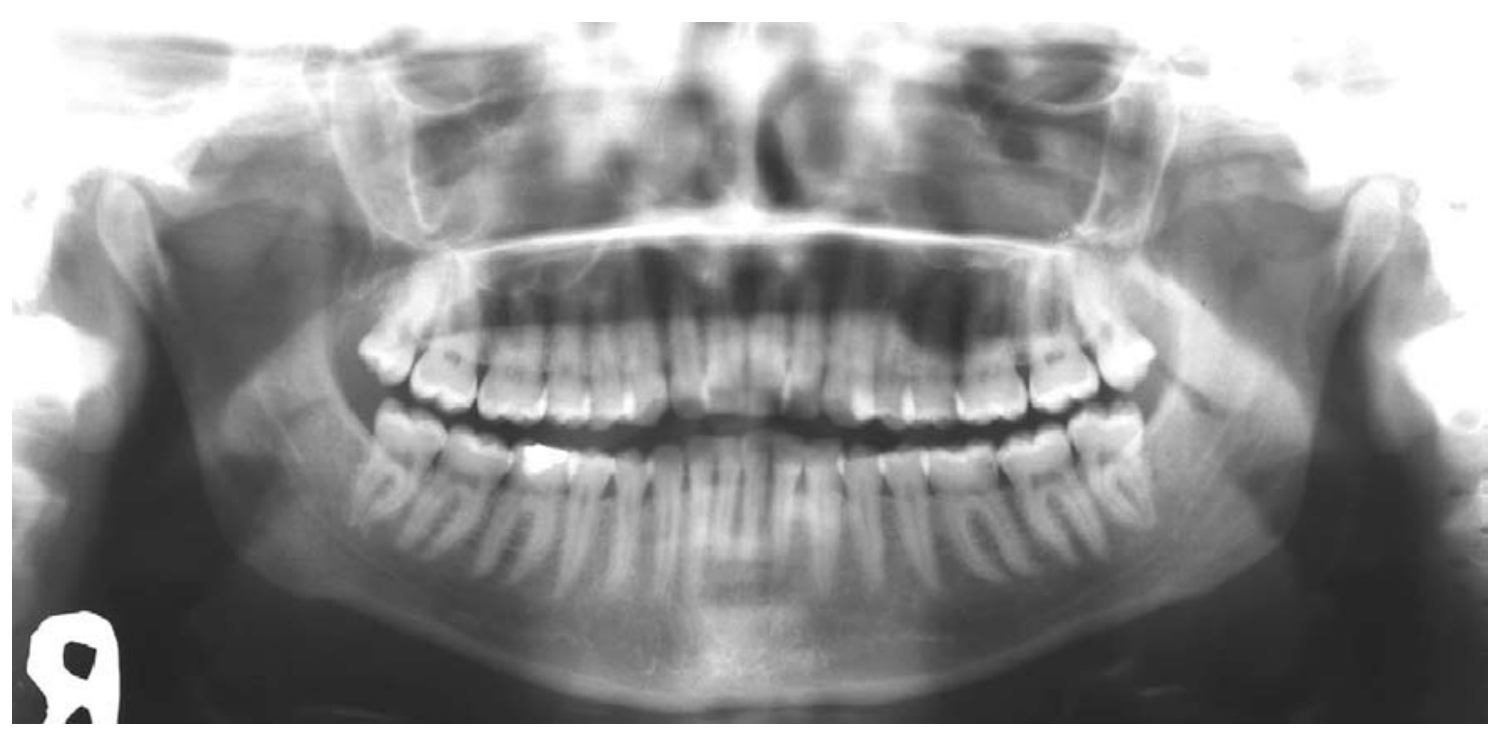

Fig. 2. Panoramic view of erupted mandibular third molar. 
a mesiangular inclination and having a completed root apex, having no periapical lesions or caries that include the pulp of MTMs, and being over the age of 20 years. In addition, those previously treated for any orthodontic problem, those having experienced trauma or having masses such as cysts or tumors in the mandible were excluded from the study. The patients in the first group ( $\mathrm{n}=60$; mean age, 25.3 years; range 21 to 38 ) had completed normal dentition with erupted mandibular third molars. The patients in the second group $(\mathrm{n}=80$; mean age, 23.04; range, 20 to 33) had impacted MTMs with mesioangular inclination. Impaction was assessed orthopantomographically if the tooth was fully embedded in the bone (Fig. 1). MTMs were classified as erupted if vertical third molars were situated at the same occlusal level as the neighboring second molars with sufficient space between the ramus and the third molars (Fig. 2).

\begin{tabular}{|c|c|}
\hline Variable & Location \\
\hline \multicolumn{2}{|l|}{ Points } \\
\hline 1 & The condyle head in contact with and tangent to the ramus plane \\
\hline 2 & The mandibular angle in contact with and tangent to the ramus plane \\
\hline 3 & The exterior turning point of the ramus and the mandibular body \\
\hline 4 & The mandibular angle in contact with and tangent to the mandibular plane \\
\hline 5 & The deepest point on the antegonial notch, \\
\hline 6 & The inferior mandibular border in contact with and tangent to the mandibular plane \\
\hline 7 & The most superior anterior convex point on the coronoid process \\
\hline 8 & The most inferior convace point on the anterior border of the ramus \\
\hline 9 & The internal turning point of the ramus and mandibular body \\
\hline 10 & The intersection of the anterior ramus border and the distal surface of the second molar \\
\hline 11 & The most superior point on the alveolar crest between the first molar and the second molar \\
\hline 12 & The most superior point on the alveolar crest between the canine and the first premolar \\
\hline 13 & The most distal convex point on the crown of the second molar \\
\hline 14 & The most mesial concex point on the crown of the second molar \\
\hline 15 & The furcation point on the root of the second molar \\
\hline 16 & The most distal convex point on the crown on the first molar \\
\hline 17 & The most mesial convex point on the crown of the first molar \\
\hline 18 & The furcation point on the root of the first molar \\
\hline 19 & The most distal convex point on the crown of the third molar \\
\hline 20 & The most mesial concex point on the crown of the third molar \\
\hline \multicolumn{2}{|l|}{ Planes } \\
\hline $1(\mathrm{rhP})$ & Ramus height-P: The distance between reference points 1 and 2 \\
\hline $2(\mathrm{rhA})$ & Ramus height-A: The distance between reference points 7 and 8 \\
\hline 3 (blu) & $\begin{array}{l}\text { Body length-U: The distance between reference points } 12 \text { and the intersection of line } 7-8 \text { (refe- } \\
\text { rence point } 7 \text { to } 8 \text { ) and line } 11-12 \text { (reference point } 11 \text { to } 12 \text { ) }\end{array}$ \\
\hline 4 (blL) & Body length-L: The distance between reference points 5 and 6 \\
\hline $5(\mathrm{rw})$ & Ramus width: The distance between reference points 3 and 9 \\
\hline $6(\mathrm{fmw})$ & First molar width: The distance between reference points 16 and 17 \\
\hline 7 (smw) & Second molar width: The distance between reference points 13 and 14 \\
\hline $8(\mathrm{sV})$ & Space-V: The distance of perpendicular line from reference point 13 to $7-8$ (reference point 7 to 8 ) \\
\hline $9(\mathrm{sH})$ & $\begin{array}{l}\text { Space-H: The distance between the intersection of line } 7-8 \text { (reference point } 7 \text { to } 8 \text { ) to line } 11-12 \\
\text { (reference point } 11 \text { to } 12 \text { ) and the intersection of perpendicular line from reference point } 13 \text { to } \\
\text { line } 7-8 \text { (reference point } 7 \text { to } 8 \text { ) }\end{array}$ \\
\hline $10(\mathrm{bwP})$ & Body width-P: The distance of perpendicular line from point 11 to line $4-6$ (reference point 4 to 6 ) \\
\hline 11 (bwA) & Body with-A: The distance of perpendicular line from point 12 to line $4-6$ (reference point 4 to 6 ) \\
\hline 12 (fmi) & $\begin{array}{l}\text { First molar inclination: The angle of first molar axis (mid point of reference points } 16 \text { and } 17 \text { to } \\
\text { reference point } 18 \text { ) and line } 4-6 \text { (reference point } 4 \text { to } 6 \text { ) }\end{array}$ \\
\hline 13 (smi) & $\begin{array}{l}\text { Second molar inclination: The angle of the second molar axis (mid point of reference points } 13 \\
\text { and } 14 \text { to reference point } 15 \text { ) and line } 4-6 \text { (reference point } 4 \text { to } 6 \text { ) }\end{array}$ \\
\hline $14(\mathrm{tmw})$ & Third molar width: The distance between reference points 19 and 20 \\
\hline \multicolumn{2}{|l|}{ Angles } \\
\hline $1(\mathrm{GaO})$ & Gonial angle-O: The angle of line 1-2 (reference point 1 to 2 ) and line $4-6$ (reference point 4 to 6 ) \\
\hline $2(\mathrm{GaL})$ & Gonial angle-I: The angle of line 7-8 (reference point 7 to 8 ) and line 11-12 (reference point 11 to 12) \\
\hline 3 (tmra) & $\begin{array}{l}\text { Third molar } 1 / 3 \text { root angle: The angle formed by the long axis drawn perpendicular to the occlusal } \\
\text { plane of the crown of the mandibular } 3^{\text {rd }} \text { molar and the central line of the lower one-third of the } \\
\text { root through the root apex. }\end{array}$ \\
\hline
\end{tabular}

Table 1. Orthopantomographic measurements of selected points, planes, and angles (Modified from Tsai, 2005)(6) 


\section{Measures}

Prior to digital orthopantomography in Oral Diagnosis and Roentgenology Clinics, objects that could interfere with the outcome and cause artifacts were removed. After dressing with a leaded apron, the patients were positioned anterior-posterior, their Frankfurt plane was parallel to the floor and the heads of all patients were stabilized to avoid distortions. All images were obtained under exposure to $60-80 \mathrm{kV}$ and $1-10 \mathrm{~mA}$ images of 3 rotation centers with constant magnification of 1.3 lasting 16.2 s (J. Marita, MFG Corp., Kyoto, Japan). On the negatoscope, the patients' chin layout was copied onto a piece of transparent paper cut the same size as the film using a $0.3 \mathrm{~mm}$ pen. Angles were measured by a protractor to the nearest $0.5^{\circ}$. Points, angles, and plane measurements are shown in Table 1.

Statistical Analysis

Because there was no difference in the panoramic measurements between the left and right mandible, data were averaged before statistical analyses were carried out. Statistical analysis was performed using SPSS version 13.0 for Windows (SPSS, Inc. Chicago, IL, USA). The Student's t-test was performed to test the effect of the third molar status and gender. The linear model included two-way interactions of the main effects. To build a model of impacted and non-impacted groups, multivariate discriminate analyses were carried out. Statistical significance was considered as $\mathrm{P}<0.05$ and the results were reported as the least square mean \pm pooled standard error.

\section{Results}

Main effects of explanatory variables

Mandibular third molar status: Erupted MTMs group had greater $\mathrm{rhP}(P<0.03)$, sV $(P<0.0001)$, sH $(P<$ $0.02)$, bwA $(P<0.0001)$ values and lower $\operatorname{rhA}(P<$ $0.0001)$, fmw $(P<0.0001)$, smw $(P<0.0001)$, tmw $(P$ $<0.0001)$, tmra $(P<0.0001), \operatorname{tmr}(P<0.0001)$, bLL $(P$ $<0.0001)$, fmi $(P<0.02)$, values than impacted MTMs group. blU value tended to be greater for erupted MTMs group than for impacted ones (Table 2).

Gender: $\operatorname{rhP}(P<0.0001), \operatorname{rhA}(P<0.0001)$, blU $(P<$ $0.003)$, rw $(P<0.0001)$, bwP $(P<0.0001)$, bwA $(P<$ $0.0001)$, tmw $(P<0.0002)$ values were lower and $\mathrm{sH}$ $(P<0.03)$ value was greater in females than for those in males. Females tended to have greater smw, fmi, and $\mathrm{GaO}$ and lower $\mathrm{GaL}$ values than males (Table 2).

The interactions among explanatory variables Mandibular third molar status by gender interaction: Diminish in bwa $(P<0.001)$, rw $(P<0.004)$, sv $(P<$

\begin{tabular}{|c|c|c|c|c|c|c|c|}
\hline \multirow[b]{2}{*}{ Variable } & \multicolumn{2}{|c|}{ Female $(n=76)$} & \multicolumn{2}{|c|}{ Male $(n=64)$} & \multicolumn{3}{|c|}{ Statistical Significance, $\mathrm{P}<$} \\
\hline & $\begin{array}{l}\text { Impacted } \\
(\mathrm{n}=42)\end{array}$ & $\begin{array}{l}\text { Erupted } \\
(\mathrm{n}=34)\end{array}$ & $\begin{array}{l}\text { Impacted } \\
(\mathrm{n}=38)\end{array}$ & $\begin{array}{l}\text { Erupted } \\
(n=26)\end{array}$ & Gender & Status & Gender $x$ Status \\
\hline $\mathrm{rhP}$ & $48.62 \pm 0.53$ & $50.66 \pm 0.59$ & $53.70 \pm 0.56$ & $55.15 \pm 0.68$ & 0.0001 & 0.003 & 0.62 \\
\hline rhA & $22.42 \pm 0.36$ & $20.74 \pm 0.40$ & $24.72 \pm 0.38$ & $22.27 \pm 0.46$ & 0.0001 & 0.0001 & 0.34 \\
\hline blU & $57.30 \pm 0.55$ & $58.81 \pm 0.61$ & $59.49 \pm 0.58$ & $60.33 \pm 0.70$ & 0.003 & 0.06 & 0.58 \\
\hline bLL & $31.41 \pm 0.76$ & $21.34 \pm 0.85$ & $31.24 \pm 0.80$ & $20.98 \pm 0.97$ & 0.76 & 0.0001 & 0.91 \\
\hline rw & $36.45 \pm 0.48$ & $37.85 \pm 0.53$ & $41.26 \pm 0.50$ & $39.50 \pm 0.61$ & 0.0001 & 0.73 & 0.003 \\
\hline fmw & $14.63 \pm 0.12$ & $14.00 \pm 0.13$ & $14.61 \pm 0.12$ & $14.10 \pm 0.15$ & 0.78 & 0.0001 & 0.63 \\
\hline smw & $14.46 \pm 0.14$ & $13.93 \pm 0.16$ & $14.41 \pm 0.15$ & $13.39 \pm 0.18$ & 0.05 & 0.0001 & 0.12 \\
\hline $\mathrm{sV}$ & $13.06 \pm 0.48$ & $19.18 \pm 0.53$ & $14.67 \pm 0.50$ & $17.90 \pm 0.61$ & 0.75 & 0.0001 & 0.007 \\
\hline $\mathrm{sH}$ & $8.55 \pm 0.31$ & $8.97 \pm 0.35$ & $7.41 \pm 0.33$ & $8.60 \pm 0.40$ & 0.03 & 0.02 & 0.27 \\
\hline bwP & $30.12 \pm 0.33$ & $32.21 \pm 0.37$ & $34.63 \pm 0.35$ & $33.27 \pm 0.42$ & 0.0001 & 0.32 & 0.0001 \\
\hline bwA & $37.29 \pm 0.40$ & $40.53 \pm 0.45$ & $40.57 \pm 0.42$ & $41.02 \pm 0.51$ & 0.0001 & 0.0001 & 0.002 \\
\hline Fmi & $83.29 \pm 0.62$ & $82.72 \pm 0.69$ & $83.09 \pm 0.65$ & $80.31 \pm 0.78$ & 0.06 & 0.02 & 0.11 \\
\hline smi & $83.41 \pm 0.50$ & $85.07 \pm 0.55$ & $84.58 \pm 0.52$ & $83.29 \pm 0.63$ & 0.58 & 0.73 & 0.008 \\
\hline $\mathrm{gaO}$ & $121.00 \pm 0.66$ & $121.68 \pm 0.74$ & $119.01 \pm 0.70$ & $120.75 \pm 0.84$ & 0.05 & 0.10 & 0.47 \\
\hline gaL & $85.27 \pm 0.61$ & $84.21 \pm 0.68$ & $86.32 \pm 0.64$ & $85.71 \pm 0.78$ & 0.06 & 0.22 & 0.73 \\
\hline tmw & $14.08 \pm 0.12$ & $13.29 \pm 0.13$ & $14.54 \pm 0.13$ & $13.81 \pm 0.15$ & 0.0001 & 0.0001 & 0.83 \\
\hline tmra & $38.73 \pm 1.78$ & $36.25 \pm 1.98$ & $45.42 \pm 1.87$ & $32.77 \pm 2.26$ & 0.42 & 0.0001 & 0.01 \\
\hline
\end{tabular}

Table 2. Effects of third mandibular molar status and gender on panoramic variables

\begin{tabular}{|c|c|c|c|c|}
\hline Variable $^{1}$ & Coefficient & $\mathrm{SE}$ & $\mathrm{P}$ & OR \\
\hline \multicolumn{5}{|l|}{ Women } \\
\hline bwA & -0.21 & 0.07 & 0.001 & $0.81(0.71-0.92)$ \\
\hline \multirow{2}{*}{$\begin{array}{l}\text { rw } \\
\text { smw }\end{array}$} & -0.20 & 0.07 & 0.004 & $0.82(0.72-0.94)$ \\
\hline & 0.47 & 0.19 & 0.02 & $1.60(1.09-2.33)$ \\
\hline $\mathrm{sV}$ & -0.28 & 0.06 & 0.0001 & $0.76(0.67-0.85)$ \\
\hline constant & 13.50 & & & \\
\hline \multicolumn{5}{|l|}{ Men } \\
\hline smw & 0.96 & 0.28 & 0.0006 & $2.62(1.51-4.54)$ \\
\hline $\mathrm{sV}$ & -0.30 & 0.08 & 0.0004 & $0.74(0.63-0.88)$ \\
\hline tmra & 0.05 & 0.02 & 0.005 & $1.05(1.01-1.08)$ \\
\hline Constant & -9.95 & & & \\
\hline
\end{tabular}

Table 3. Coefficients and odd ratio of factors affecting impactness of mandibular third molar status 
$0.0001)$ values and increase in smw $(P<0.02$ value for female when their MTMs were impacted. Diminish in $\mathrm{sV}$ $(P<0.0004)$ value and increase in, smw $(P<0.0006)$, tmra $(P<0.005)$ values for male when their MTMs were impacted (Table 3 ).

\section{Discussion}

Imaging methods may have caused the variability in the literature dealing with predicting third molar status. It appears that panoramic radiography is a reliable and common method for evaluating the mandibular third molar (MTMs) status and relevant measurements as well as linear dimensions and angles of the mandible $(2,6,10,11)$. In this experiment, equipment was fixed at a constant magnification and patients were prepared according to the radiography protocol. Thus, numerical differences between the left and right mandible measurements was minimal and could be due to inevitable distortions that might result from patient movement at the time of imaging. In addition to imaging methods, the patients' age is also important. Due to positional changes occurring during third molar development, prediction of the third molar status based on variables measured before age 20 may not be reliable $(2,10)$, suggesting that predictive variables should be collected after completion of the positional changes ( $>20$ years old).

The increasing incidence of third molar impaction is of great concern (2). Although numerous publications are available on this topic, the etiology of the impacted MTM has not been fully elucidated. Kaplan (12) postulated that there was a direct relationship between facial development and growth and positions of the MTM. Eruption or impaction of the third molars depends on genetics and race as well as other factors such as the degree of mastication, dietary habits, and extent of generalized tooth attrition $(2,8,13)$. In relation to dietary factors, it was shown that the incidence of impaction was less in undeveloped countries than in developed countries (14).

Many studies have revealed that insufficiency of the retromolar surface area is associated with impaction of the MTM $(2,5,14)$. Ganss et al. (5) evaluated rotational tomograms and lateral cephalometric radiographs in 75 patients. Based on follow up 3 and 7 years later, they found that $70 \%$ of the MTMs were erupted if the ratio of retromolar space to tooth width was greater than 1. However, Hattab and Alhaija (2) reported that $17 \%$ of third molars failed to erupt, although this ratio was greater than 1. Similarly, Björk and Skieller (15) used metallic implants in three locations to monitor mandibular growth and development and showed that small retromolar space accounted for $90 \%$ of MTM impaction. Contrary to the reports of some scientists that there is no relationship between the retro molar space and third molar status $(8,10,16,17)$, it is shown in our study that insufficient retro molar space plays a role in causing the MTM to remain impacted (Table 2).

The MTM develops in the ramus of the mandible; its occlusal surface faces upwards and forwards and as a space becomes available for it due to growth of the mandible, it rotates into a more upright position. Therefore, space for third molar eruption is created partially by the forward movement of the dentition and partially by the resorption of bone at the back of the dental arch. The pattern of growth that influences this space should be considered (6). If resorption of the anterior border of the ascending ramus and horizontal growth of the mandible does not occur, the third molar remains in the bone $(14,18)$. $\mathrm{Ng}$ et al. (3) postulated that depressed alveolar development was responsible for impaction of the third molars. However, results reported by Tsai (6) were in disagreement with this theory. Based on our data, we think that the eruption of teeth with a mesioangular inclination caused by anterior movements of the molars is responsible, rather than partial resorption at the anterior border of the ramus. As a result, alveolar crest length and ramus width could be independent from eruption (Table 2).

Mesial drift of the posterior teeth results in excessive interproximal attrition and consequently to increased retromolar space (14). Pulling premolar teeth out is associated with a decreased rate of impaction of third molars $(6,19)$ whereas pulling molar teeth out eliminates the chance of third molar impaction (19). Early loss of deciduous molars or first molar accelerates the eruption of third molars (11). This could be attributed to an increased eruption surface area resulting from mesial movement of the molar teeth during extraction-site closure (14). Kaplan (19) reported that the MTMs impaction could occur when premolars were extracted, which possibly resulted from insignificant resorption along the anterior border of the ramus. According to the author, this could be associated with an increased vertical ramus growth. A greater vertical height of the anterior border of the ramus in impacted third molars partially supports the findings of Kaplan (Table 2).

Tooth diameter is also proposed as a descriptive variable for the third molar status. Impacted third molars were shown to have a greater diameter $(3,13)$. However, some authors (2) found no difference in the diameters of erupted and impacted third molars. Tsai showed that first molars had a greater diameter when third molars were impacted (6). Our results suggest that third molar status depends on the diameters of first and third molars as well as second ones, which may reflect the importance of chin morphology.

Movements of the mandible and teeth may cause some morphological alterations at the bottom $1 / 3$ part of the root. Despite being in a similar position, these effects can be different on the left and right third molars. The bottom $1 / 3$ part of the root is especially affected when 
the anterior border of the ramus is resorbed and the corpus mandible is enlarged $(18,20)$. Yamaoka et al. (18) reported the presence of angled-roots in impacted third molars, especially in females. In the present study, angled-roots affected impaction in both genders (Table 2). In addition, increase in the number of roots adversely affected the MTM status. Due to occupying a relatively larger space and limiting eruption surface, third molars with multiple roots may be prone to impaction (Table 2).

According to the data obtained in this study, the vertical height of the anterior border of the ramus, length of the posterior basal corpus, mesio-distal diameters of the first, second and the third molars, $1 / 3$ root angle of the third molar, number of third molar roots, inclination of the first molar to increase, vertical height of the posterior border of the ramus, vertical height of alveolar crest, and height and the width of the retro-molar space to decrease are all in direct proportion to the possibility of impaction of the MTM.

\section{References}

1. Badawi Fayad J, Levy JC, Yazbeck C, Cavezian R, Cabanis EA. Eruption of third molars: relationship to inclination of adjacent molars. Am J Orthod Dentofacial Orthop. 2004;125:200-2.

2. Hattab FN, Alhaija ES. Radiographic evaluation of mandibular third molar eruption space. Oral Surg Oral Med Oral Pathol Oral Radiol Endod. 1999;88:285-91.

3. Ng F, Burns M, Kerr WJ. The impacted lower third molar and its relationship to tooth size and arch form. Eur J Orthod. 1986;8:254-8.

4. Niedzielska IA, Drugacz J, Kus N, Kreska J. Panoramic radiographic predictors of mandibular third molar eruption. Oral Surg Oral Med Oral Pathol Oral Radiol Endod. 2006;102:154-8; discussion 159.

5. Ganss C, Hochban W, Kielbassa AM, Umstadt HE. Prognosis of third molar eruption. Oral Surg Oral Med Oral Patho.1 1993;76:68893.

6. Tsai HH. Factors associated with mandibular third molar eruption and impaction. J Clin Pediatr Dent. 2005;30:109-13.

7. Punwutikorn J, Waikakul A, Ochareon P. Symptoms of unerupted mandibular third molars. Oral Surg Oral Med Oral Pathol Oral Radiol Endod. 1999;87:305-10.

8. Polat HB, Ozan F, Kara I, Ozdemir H, Ay S. Prevalence of commonly found pathoses associated with mandibular impacted third molars based on panoramic radiographs in Turkish population. Oral Surg Oral Med Oral Pathol Oral Radiol Endod. 2008;105:41-7.

9. Henry C, Morant G. A preliminary study of the eruption of the mandbular third molar tooth in man based on measurements obtained from radiographs, with special reference to the problem of predicting cases of ultimate impaction of the tooth. Bijometrika. 1936;28: 378-427.

10. Ventä I, Schou S. Accuracy of the Third Molar Eruption Predictor in predictin eruption. Oral Surg Oral Med Oral Pathol Oral Radiol Endod. 2001;9:638-42.

11. Yavuz I, Baydaş B, Ikbal A, Dağsuyu IM, Ceylan I. Effects of early loss of permanent first molars on the development of third molars. Am J Orthod Dentofacial Orthop. 2006;130:634-38.

12. Kaplan RG. Mandibular third molars and postretention crowding. Am J Orthod. 1974;66: 4114-30.

13. Ventä I, Murtomaa H, Ylipaavalniemi P. A device to predict lower third molar eruption. Oral Surg Oral Med Oral Pathol Oral Radiol Endod. 1997;84:598-603.

14. Behbehani F, Artun J, Thalib L. Prediction of mandibular thirdmolar impaction in adolescent orthodontic patients. Am J Orthod Dentofacial Orthop. 2006;130:47-55.

15. Björk A, Skieller V. Facial development and tooth eruption. An implant study at the age of puberty. Am J Orthod. 1972;62:339-83. 16. Richardson ME. Late lower arch crowding in relation to primary crowding. Angle Orthod. 1982;52:300-12.

17. Ventä I, Schou S. Application of the Third Molar Eruption Predictor to periapical radiographs. Clin Oral Investig. 2001;5:129-32.

18. Yamaoka M, Furusawa K, Hayama H, Kura T. Relationship of third molar development and root angulation. J Oral Rehabil. 2001;28:198205.

19. Kaplan RG. Some factors related to mandibular third molar impaction. Angle Orthod. 1975;45:153-8.

20. Marklund M, Persson M. The relationship between mandibular morphology and apical root curvature in man. Arch Oral Biol. 1988;33:391-4.

\section{Acknowledgements}

Special thanks to, Dr. Armağan Hayırlı for his assistance with the statistical analysis. 